\title{
Время истории
}

\section{АНДРЕЙ ОЛЕЙНИКОВ}

Заведующий, кафедра политических и правовых учений, факультет политических наук, Московская высшая школа социальных и экономических наук (МВШСЭН); старший научный сотрудник, лаборатория историко-культурных исследований, Школа гуманитарных исследований (ШАГИ), Институт общественных наук (ИОН), Российская академия народного хозяйства и государственной службы при Президенте РФ (РАНХиГС).

Адрес: 119571, Москва, пр-т Вернадского, 82. E-mail: andrey.oleynikov@gmail.com.

Ключевые слова: темпоральный поворот; множественная темпоральность; практическое прошлое; радикальный историзм; учредительная власть; ретроактивность; контингентность.

В статье утверждается, что так называемый темпоральный поворот, наблюдаемый сегодня в теории исторической науки, не только расширяет предметную область истории (что позволяет включить в нее ранее малоисследованные вопросы, связанные со способами переживания и упорядочивания времени в эпохи, которые предшествуют институционализации исторического знания и формированию линейной темпоральности классического историзма), но также позволяет заново поставить вопрос о ее практическом назначении, «о пользе и вреде истории для жизни». Автор статьи предлагает рассматривать этот вопрос через призму идеи «реполитизации историографии», предложенной Мишелем де Серто в 1980-е годы.

Принятая в качестве исследовательской стратегии «реполитизация», по мнению автора, может разворачиваться в двух модусах: а) в качестве критики установки профессиональной историографии на приобретение максимального объективного знания о прошлом, которое считается принципиально отличным от настоящего и несовместимым с ним, и б) в качестве особой практико-ориентированной философии истории, которую предлагается называть «радикальным историзмом». В первом случае критика сближается с программой изучения «практического прошлого», содержащейся в последней прижизненной книге Хейдена Уайта с одноименным названием, где он заявляет об антагонизме так называемого исторического прошлого, создаваемого профессиональными историками, и практического прошлого, доступного всем обычным людям без исключения. Автор предлагает собственный подход к концепции радикального историзма, вдохновляясь работами Марка Бевира, а также идеями ряда известных марксистских мыслителей и теоретиков радикальной демократии. В целом радикальный историзм характеризует контингентная онтология исторического события (его радикальная новизна) и неприятие настоящего положения дел (в котором живет историк) в качестве «закономерной» констелляции исторических сил и процессов. 
Сегодня необходимо "реполитизировать» науки, навести их технический аппарат на те силовые поля, в которых они действуют и производят свой дискурс. И в этом по преимуществу состоит задача историка. <...> Технически эта "реполитизация» будет состоять в «историзации» самой историографии.

Мишель де Серто. Гетерологии ${ }^{1}$

\section{Темпоральный поворот и «реполитизация» истории}

\section{$\Pi$}

РЕИМУЩЕСТВО истории перед другими науками - нередко признаваемая за ней способность подвергать ревизии и делать предметом исследования свои же собственные недавние предпосылки - в глазах Мишеля де Серто подрывалось одним очень серьезным недостатком: специфическим обращением со временем. Дело в том, что историки склонны «подменять знакомство со временем знанием о том, ито существует во времени» ${ }^{2}$. В лучшем случае они используют его как инструмент классификации в виде хронологии, которую де Серто называл «алиби времени», способом обращаться с ним, не слишком о нем задумы-

Статья подготовлена в рамках выполнения научно-исследовательской работы государственного задания РАНХиГС «Этические аспекты исторического знания как предмет философии истории 2010-х годов».

1. De Certeau M. Heterologies: Discourse on the Other. Minneapolis: University of Minnesota Press, 1986. Р. 215. Для де Серто «реполитизация»-это способ занять сторону этики в ее конфликте с догматизмом: «Этика артикулируется посредством действенных операций и определяет дистанцию между тем, что есть, и тем, что должно быть. Расстояние между ними обозначает пространство, где нам есть что делать. С другой стороны, догматизм получает свои полномочия от реальности, которую претендует репрезентировать, и от имени этой реальности он навязывает законы. Историография функционирует посредине между этими двумя полюсами: но всякий раз, когда она пытается оторваться от этики, она обращается к догматизму» (Ibid. P. 199).

2. Фраза принадлежит историку Жерару Мэре, которого де Серто с одобрением цитирует (Idem. The Writing of History. N.Y.: Columbia University Press, 1988. P. 12). 
ваясь ${ }^{3}$. За пределами интереса историков находится то исходное неравенство между прошлым и настоящим, благодаря которому историография обретает свою предметность, нуждающуюся в особом научном контроле и особых местах хранения в виде архивов, музеев и библиотек. У самого же де Серто не было никаких сомнений в том, что

... внутри социально стратифицированной реальности историография устанавливает в качестве «прошлого» (то есть совокупности странных черт и «противодействий», которые следует принять или отвергнуть) все то, ито не относилось к власти над производством настоящего, является ли эта власть политической, социальной или научной ${ }^{4}$.

Но сегодня, спустя почти сорок лет после выхода в свет этих размышлений, мы наблюдаем ситуацию, которая могла бы определенно порадовать их автора. За первые два десятилетия нового века появилась целая серия блестящих работ, в которых не только подвергнуто историзации принимаемое ранее без всякой рефлексии различие между прошлым и настоящим ${ }^{5}$, но и исследована генеалогия каждого из них в отдельности, так что теперь благодаря Захари Шиффману ${ }^{6}$ мы знаем, что еще в эпоху Ренессанса прошлое не было отделено от настоящего непроходимой пропастью, а благодаря Ахиму Ландверу ${ }^{7}$ принимаем в расчет, что модерное чувство настоящего заявило о себе впервые тогда, когда один швейцарский врач обнаружил смертельную тоску по дому у своих соотечественников, покинувших родные края в поисках лучшей доли, и прозвал ее «ностальги-

3. Idem. Heterologies. Р. 216. Эти рассуждения де Серто вдохновили американского историка Стивена Танаку на проект «История без хронологии» (Tanaka S. History Without Chronology. Amherst, MA: Lever Press, 2019).

4. De Certeau M. Heterologies. P. 216. Курсив мой. - A. O.

5. Прорывной работой в этом направлении, на мой взгляд, является сборник: Breaking Up Time: Negotiating the Borders Between Present, Past and Future/C. Lorenz, B. Bevernage (eds). Göttingen: Vandenhoeck \& Ruprecht, 2013. См. мою рецензию на него: Олейников А. Откуда берется прошлое? (Апология анахронизма) //Новое литературное обозрение. 2014. № 2. C. $337-344$.

6. См.: Schiffman Z.S. The Birth Of The Past. Baltimore: Johns Hopkins University Press, 2011.

7. См.: Landwehr A. Nostalgia and the Turbulence of Times// History and Theory. 2018. Vol. 57. № 2. P. 251-268; Idem. Geburt der Gegenwart. Eine Geschichte der Zeit im 17. Jahrhundert. Fr.a.M.: Fischer, 2014. 
ей». В ходе этих исследований была релятивизована парадигма необратимого и однонаправленного времени, установившаяся в период господства классического историзма. Сегодня среди специалистов по теории истории все большей популярностью пользуются концепции многослойного или множественного исторического времени, допускающие сосуществование разнородных темпоральных режимов внутри той крайне неустойчивой их констелляции, которую мы признаем в качестве «нашей» современности. Так что впору говорить о том, что в теории исторического знания происходит «темпоральный поворот», который, как и почти все предшествующие «повороты», включая «лингвистический», «культурный», «имперский», «глобальный» и «пространственный», обещает открыть новые исследовательские горизонты, на этот раз-в истории конструирования и восприятия времени, и кажется, что эти обещания начинают уже во многом сбываться ${ }^{8}$.

Однако наш тематический номер посвящен другой, не столь триумфальной стороне этого темпорального поворота, который, как мне представляется, оборачивается серьезным испытанием для дисциплинарных основ исторического знания, требуя радикальных изменений в их теоретизировании. До сих пор достаточным основанием (и нередко главным предметом) последнего выступали институциональные практики производства все того же знания. Ни глубокомысленные рассуждения о структурах историчности хайдеггеровского образца, ни знаменитый разрыв между «пространством опыта» и «горизонтом ожидания», объясняющий ускорившийся с середины XVIII века ход мировой истории согласно Райнхарту Козеллеку, не говоря уже о теориях прогресса во всевозможных его версиях, не образуют столь прочного консенсуса в понимании истории, какой следует из простого признания давнего существования одноименной культурной практики, осуществляемой сегодня по преимуще-

8. Число интересных работ, вышедших по этой тематике за последние десять лет, уже достаточно велико, чтобы можно было их здесь все перечислить. Но в качестве введения в проблему я рекомендовал бы следующие тексты: West-Pavlov R. Temporalities. L.; N.Y.: Routledge, 2013; Lorenz C. 'The Times They Are a-Changin'. On Time, Space and Periodization in History // Palgrave Handbook of Research in Historical Culture and Education / M. Carretero et al. (eds). L.: Palgrave Macmillan, 2017. P. 109-131; Tamm M., Olivier L. Introduction. Rethinking Historical Time// Rethinking Historical Time. New Approaches to Presentism/M. Tamm, L. Olivier (eds). L.: Bloomsbury Academic, 2019. P. 1-20. 
ству в стенах академических учреждений. Ссылки на их авторитет бывает достаточно, когда требуется ответить на вопрос, что же такое история: это то, чем занимаются академические историки. Это обстоятельство могло бы послужить непреодолимым аргументом в пользу необычайной самодостаточности профессиональной историографии, ее удивительной способности сохранять верность идеалам беспристрастности и объективности, обходя все новомодные «теоретические» искушения, если бы эти идеалы оставались одними и теми же во все времена, а историки жили бы вне социума и заботились бы исключительно о корректном изложении событий, «как они были на самом деле». Тем не менее трудно отрицать, что между теми, кто пишет истории, и теми, кто размышляет об их смысле и предназначении, зачастую царит отчуждение, которое, впрочем, гораздо больше волнует последних, чем первых. Одним из недавних ярких свидетельств недовольства таким состоянием дел стал опубликованный онлайн в 2018 году манифест под названием «Тезисы о теории и истории», принадлежащий Итану Клейнбергу, Джоан Скотт и Гари Уайлдеру․을 изобилует инвективами в адрес «дисциплинарной истории» за ее в целом «антитеоретическую и нерефлексивную ориентацию» ${ }^{10}$. Профессиональные историки, по мнению авторов, если и воспринимают теорию, то в лучшем случае в виде «методологии», польза от которой сводится к упорядочению фактического материала и его контекстуализации. За подобным «методологическим фетишизмом» стоит не подвергаемая сомнению верность «онтологическому реализму», которая говорит о том, что эпистемологически академическая историография продолжает пребывать в XVIII веке. Внимание к изменчивым сторонам социальной жизни могло бы сделать ее более открытой для критической теории в ее разнообразных современных версиях, однако, как пишут авторы, зачастую «радикальные эпистемологические исследования Фуко становятся

9. Kleinberg E. et al. Theses on Theory and History. URL: http://theoryrevolt.com. Итан Клейнберг - профессор Уэслианского университета, главный редактор журнала Theory and History, исследует влияние деконструкции Жака Деррида на теорию истории. Джоан Уоллак Скотт - одна из основателей журнала History of the Present: A Journal of Critical History, ведущий американский феминистский и гендерный историк. Гари Уайлдер - профессор антропологии Городского университета Нью-Йорка, автор работ по колониальной истории.

10. Ibid. P. 4. 
просто еще одним исследованием тюрем, клиник или сексуальных практик», "марксизм сводится к экономическому детерминизму или применению категории „класс“ к исследованию местных сообществ, а „гендер“ дублирует различие между полами или стойкую противоположность между мужчиной и женщиной, где бы о ней ни говорили» ${ }^{11}$. Авторы манифеста полагают, что господство нерефлексивной «дисциплинарной истории» может быть подорвано только с помощью так называемой критической истории, которая

...не применяет теорию к истории и не призывает к тому, чтобы в исторических работах было больше теории, как если бы она бралась откуда-то со стороны. Скорее она нацелена производить теоретически поучительную историю и исторически обоснованную теорию ${ }^{12}$.

Правда, подобная «критическая» альтернатива фигурирует в этом тексте скорее как идеал, указывающий на то, как следует работать историкам в наши дни, поскольку его авторы даже не сочли нужным (или возможным) подкрепить его ссылками на уже имеющиеся работы подобного рода. Однако при всей его очевидной прекраснодушности два пункта из описания этого идеала выдают не просто недовольство авторов актуальным состоянием дисциплины, но их желание покончить наконец с ее гегемонией в определении существа истории:

Критическая история... старается оспорить саму логику прошлого и настоящего, теперь и тогда, здесь и там, нас и их, от которой зависит как дисциплинарная история, так и действующий социальный порядок.

Критическая история старается вмешиваться в общественные дебаты и политическую борьбу. Но, не ища сотрудничества с властью в качестве специальных экспертов, она ставит под сомнение сведение мышления к учености, ученых - к специализации и саму идею власти экспертов ${ }^{13}$.

В этом, на мой взгляд, заключается основная сегодняшняя ставка наиболее радикальных протагонистов темпорального поворота. Речь идет не просто о переоткрытии времени в качестве еще одной предметной области современной исторической на-

11. Ibid. P. 6, 7 .

12. Ibid. Р. 8. Курсив авторов.

13. Ibid. Р. 10. Курсив авторов. 
уки. Сколь бы увлекательным ни было изучение домодерных или неевропейских форм переживания времени, как бы ни убеждались мы в долговременности религиозных и прочих культурных «предрассудков», еще недавно признаваемых анахронизмами, именно в «реполитизации» исторического знания, о которой писал Мишель де Серто, состоит главный смысл интересующего нас сдвига в отношении к истории. У этой «реполитизации»есть, условно говоря, «более теоретическая» и «более инструментальная» стороны. Они редко обходятся друг без друга, однако последняя, сводимая к участию в различного рода «исторических войнах» или «войнах памяти», нас здесь интересовать не будет. Далее я сосредоточусь на том, что представляет собой ее первая сторона.

\section{Два модуса «реполитизации»}

Первый из двух ее важнейших модусов состоит в стремлении вернуть историческому знанию его первоначальное морально-практическое измерение в качестве magistra vitae, утраченное, когда это знание превратилось в профессиональную науку. Эту перспективу ясно обозначил Хейден Уайт в своей последней прижизненной книге, в которой он заявил об антагонизме двух главных способов обращения с прошлым - так называемого исторического прошлого, создаваемого профессиональными историками, и практического прошлого, доступного всем обычным людям без исключения ${ }^{14}$. «Историческое прошлое», как пишет Уайт, существует только в научных работах, его «никто никогда не проживал и не испытывал». Оно создается только в целях познания и «не содержит указаний на то, как действовать в настоящем или предвидеть будущее» ${ }^{15}$. «рактическое прошлое», напротив, содержит подобные указания. Мы постоянно полагаемся на них в повседневной жизни: «это прошлое памяти, мечты и желания в той же мере, как и прошлое, необходимое для принятия решения, стратегии и тактики жизни, личной и совместной» ${ }^{16}$. Оно является практическим потому, что полезно не только в широком житейском смысле, но и в этическом, кантовском смысле, поскольку предлагает свою помощь в ответе на вопрос: «Что мне следует делать?»

14. White H. The Practical Past. Evanston, IL: Northwestern University Press, 2014. 15. Ibid. P. 9.

16. Ibidem. 
Однако было бы заблуждением считать, что профессиональное занятие историей напрочь лишено практического смысла. Согласно Уайту, он состоит в том, чтобы

...служить интересам национального государства, помогать в создании национальных идентичностей и использоваться при обучении педагогов, политиков, колониальных администраторов, политических и религиозных идеологов ${ }^{17}$.

Уайт не просто критикует профессиональную историографию за то, что она далека от житейских забот, но прежде всего выступает против определенной «политики интерпретации» ${ }^{18}$, которой она подчиняется. Эта политика проводится с начала XIX века с тем, чтобы превратить историческую дисциплину «в блюстителя реализма в политическом и социальном мышлении» ${ }^{19}$. Направленная против всяческого утопизма, без которого немыслима радикальная политика справа или слева, она заставила историографию оборвать ее былые связи с риторикой и прочей «изящной словесностью», которой стала вменяться ее прежняя функция - создавать модели поведения для «исполнения общественных дел» ${ }^{20}$. Сама же историография, став наукой, имеющей дело исключительно с документальными фактами, была призвана подтверждать необратимость событий, приведших в конечном счете к торжеству того относительно благополучного настоящего, в котором живет историк. Эта политика стала давать серьезные сбои в XX веке, когда целая серия «холокостоподобных» ${ }^{21}$ катастроф вызвала появление нового прошлого, которое, по известному выражению Эрнста Нольте, «не собирается уходить» ${ }^{22}$. Упорно присутствуя в социальной и культурной памяти, оно тревожит академических историков, поскольку ставит под сомне-

17. Ibid. P. 15.

18. См.: Idem. The Politics of Historical Interpretation: Discipline and De-Sublimation // Critical Inquiry. 1982. Vol. 9. № 1. P. 113-137.

19. Ibid. P. 117, 118.

20. Idem. The Practical Past. P. 10.

21. К так называемым "holocaustal" events Уайт относит две мировые войны, Великую депрессию, создание ядерного оружия, появление новых коммуникационных технологий и истощение природных ресурсов. См.: Idem. The Modernist Event//Idem. Figural Realism. Studies in the Mimesis Effect. Baltimore: Johns Hopkins University Press, 1999. P. 66-86.

22. Nolte E. Vergangenheit, die nicht vergehen will// Historikerstreit. Die Dokumentation der Kontroverse um die Einzigartigkeit der nationalsozialistischen Judenvernichtung. München; Zürich: Piper, 1987. S. 39-46. 
ние их умение непредвзято различать сохраняющий и утративший свою актуальность порядок вещей. Именно такое прошлое Уайт называет «практическим». С его осмыслением, как он считает, лучше справляется свидетельская литература, как, например, воспоминания Примо Леви «Человек ли это?», и документальнохудожественная проза, как роман Винфрида Зебальда «Аустерлиц». Различие между фактом и вымыслом в этих сочинениях если и не снимается полностью, то определенно утрачивает тот конститутивный смысл, который оно имеет для профессиональной историографии ${ }^{23}$.

Отсюда становится понятным, что для теории истории, ставящей на первое место вопрос о ее, по словам Юргена Хабермаca, «публичном употреблении» ${ }^{24}$, ключевой является проблема неопределенности границ между прошлым и настоящим, известная сегодня как проблема презентизма. На мой взгляд, можно выделить два основных направления в ее разработке. В одном из них предпочитают действовать главным образом академические историки. Презентизм здесь означает аномалию в обращении с прошлым ${ }^{25}$. Обнаруженная относительно недавно, она характеризуется двумя тесно переплетенными чертами: чрезвычайной зави-

23. Стоит при этом отметить одну серьезную проблему концепции практического прошлого: за ней не просматривается сколько-нибудь отчетливая «политика интерпретации», подобная той, которую Уайт обнаружил и раскрыл применительно к профессиональной историографии XIX века. Последняя, как он убедительно показал в свое время, приучала верить в естественную природу исторического факта, чтобы с его помощью оправдывать порядок, установившийся в настоящем. Но какая политика движет исследователем, который, следуя заветам Уайта, хочет поставить прошлое на службу будущему? Сам Уайт не слишком помогает нам с ее определением. На мой взгляд, британские исследователи Клэр Нортон и Марк Донелли дали достаточно взвешенное и точное определение его позиции, назвав ее «надполитической». По их словам, Уайт «призывал восстановить „моральное воображение“ в исторической мысли, оставив нас в неведении относительно содержания, которое такая мысль могла бы в итоге иметь» (Norton C., Donnelly M. Liberating Histories. L.: Routhledge, 2018. P. 151).

24. Habermas J. Concerning the Public Use of History// New German Critique. 1988. № 44 (Special Issue on the Historikerstreit). P. 40-50. См. также: Idem. Eine Art Schadensabwicklung. Die apologetischen Tendenzen in der deutschen Zeitgeschichtsschreibung // Historikerstreit. Die Dokumentation der Kontroverse um die Einzigartigkeit der nationalsozialistischen Judenvernichtung. S. $62-76$.

25. Hartog F. Regimes of Historicity. Presentism and the Experiences of Time. N.Y.: Columbia University Press, 2015. 
симостью историка от настоящего, в котором он живет, и утратой способности видеть в прошлом «другой мир» или «чужую страну». Эта возрастающая зависимость от настоящего сказывается прежде всего в том, что можно назвать «юридификацией» прошлого $^{26}$. Принимая так называемые мемориальные законы, диктующие определенную трактовку исторических событий, государство лишает историка права на их независимую оценку. В данном случае он утрачивает преимущества, которые были закреплены за его профессией. Но те же самые преимущества могут превращаться в свою противоположность и тогда, когда историка на правах эксперта привлекают к судебным разбирательствам, которые ведутся по делам, квалифицируемым как «преступление против человечества, не имеющее срока давности» ${ }^{27}$, или к работе так называемых комиссий по установлению истины и справедливости, создававшихся на рубеже XX-XXI веков в ряде стран, переживавших переход от авторитарных к номинально демократическим политическим режимам, ради достижения гражданского мира и согласия ${ }^{28}$. Различительная способность историка может страдать не только от предвзятости и ангажированности, но и от сверхдоступности прошлого в современную цифровую эпоху. Об этом пишет Ханс-Ульрих Гумбрехт, полагающий, что сегодня мы живем в условиях «широкого настоящего» (broad presence), когда прошлое и будущее не противопоставляются настоящему в качестве его «иного», но фактически поглощаются им, становясь его имманентными измерениями и притупляя тем самым наше историческое сознание ${ }^{29}$.

Во всех этих случаях презентизм мыслится как некоторое кризисное состояние, наступившее относительно недавно (Франсуа Артог даже датирует его наступление 1989 годом), сменив более благополучное время, когда историки гораздо отчетливей видели разницу между прошлым и настоящим. Такое его уподобление отдельному периоду или эпохе на оси линейного времени вызывает критику у ряда теоретиков истории, склонных сомневаться в равенстве настоящего самому себе и разделяющих скепсис Деррида по отношению к тому, что тот называл

26. Термин Криса Лоренца (см. его статью в настоящем номере «Логоса»).

27. Cm.: Koposov N. Memory Laws, Memory Wars: The Politics of the Past in Europe and Russia. Cambridge: Cambridge University Press, 2018.

28. Cм.: Bevernage B. History, Memory, and State-Sponsored Violence: Time and Justice. L.; N.Y.: Routledge, 2012.

29. Gumbrecht H. U. Our Broad Present: Time and Contemporary Culture. N.Y.: Columbia University Press, 2014. 
«метафизикой присутствия» ${ }^{30}$. Они воспринимают презентизм скорее как чрезвычайно благоприятную ситуацию для осмысления механизмов синхронизации разнородных темпоральностей, которые создают впечатления о самотождестве настоящего и утверждают его превосходство над прошлым. В нашем выпуске такой позиции придерживается нидерландский философ Крис Лоренц, показывающий в своей статье, что презентизм по сути является синонимом "режима историчности»- другого известного понятия, введенного Артогом для описания отношений между прошлым, настоящим и будущим, когда одно из них оказывается доминирующим в зависимости от историко-культурной ситуации. Однако Лоренц настаивает на том, что презентизм следует мыслить не как хронологический «временной блок», а как аналитический инструмент, подобный веберовскому «идеальному типу». Иными словами, польза от его употребления состоит в релятивизации условий, позволяющих видеть различие между прошлым и настоящим, и их несводимости к оптике, которую использовала профессиональная историография XIX-XX веков.

Другой чрезвычайно важный модус «реполитизации» исторического знания с подачи британского философа Марка Бевира я определил бы как радикальный историзм. Что это такое? С точки зрения Бевира, историзм существует в двух своих основных версиях - девелопментальной и радикальной. Классический историзм XIX - первой половины XX века по преимуществу девелопментальный. Среди его «отцов-основателей»Огюст Конт, Георг Вильгельм Фридрих Гегель, Карл Маркс и Герберт Спенсер. Несмотря на громадную разницу философских мировоззрений, их объединяет то, что они создавали нарративы о непрерывной и поступательной развертке во времени тех или иных системообразующих принципов. Именно такой историзм, тесно связанный с идеей прогресса, как мы могли заметить, был серьезно дискредитирован в XX веке усилиями Карла Поппера, Фрэнсиса Фукуямы и теоретиков «лингвистического поворота».

Однако, по мысли Бевира, склонность видеть смысл в изменяющихся условиях нашего существования отнюдь не обрекает

30. См.: Бевернаж Б. Аллохронизм, равенство во времени и современность. Критика проекта радикальной современности Йоханнеса Фабиана и доводы в пользу новой политики времени // Социология власти. 2016. № 2. C. $174-202$. 
нас на то, чтобы становиться сторонниками девелопментального историзма и верить в неуклонный научный или социальный прогресс. Радикальный историзм строится на идее контингентности (непредопределенности) социальных изменений и допускает обратимость исторических процессов. Главными его ревнителями Бевир объявляет Фридриха Ницше и Мишеля Фуко. Чем же эти две версии историзма отличаются друг от друга? Для наглядности Бевир сравнивает их по трем критериям ${ }^{31}$.

1. Взгляд на историю (view of history). У девелопментального историзма - эволюционный. Его адепты создают нарратив о последовательном и неизбежном триумфе, к примеру, избранной нации или социального равенства. Радикальные истористы, напротив, представляют историю в виде «серии контингентных, случайных присвоений, модификаций и преобразований старого в новое» ${ }^{32}$. Бевир цитирует Ницше, писавшего, что

... причина возникновения какой-либо вещи и ее конечная полезность, ее фактическое применение и включенность в систему целей toto coelo расходятся между собой ${ }^{33}$.

Этот акцент на контингентности исторических явлений не следует принимать за свидетельство их принципиальной непознаваемости. Просто сторонники радикального историзма отказываются объяснять интересующие их явления, апеллируя к фундаментальным и сверхисторическим принципам. Они предпочитают объяснять их в терминах новых вызовов, которые вступают в конфликт со старыми ценностями и ставят под сомнения устоявшиеся интерпретации. История, с их точки зрения, не завершена, а исторические смыслы открыты для переинтерпретации.

2. Взгляд на соииальное объяснение (view of social explanation). Девелопментальный историзм тяготеет к телеологическому объ-

31. Бевир приводит это сравнение в работе: Bevir M., Rhodes R. A. W. Three Visions of Context and History // Contest in Public History and Management: The Missing Link? / C. Pollit (ed.). Aldershot: Edward Elgar, 2013. Р. 55-73. Помимо двух названных видов историзма, он также выделяет в ней так называемый модернистский эмпиризм как промежуточную форму историзма, характерную для эмпирических исследований в социальных науках, но она существенно не осложняет картину противостояния девелопментального и радикального историзма.

32. Bevir M. Historicism and Critique// Philosophy of the Social Sciences. 2015. Vol. 45. № 2. P. 230.

33. Нищще Ф. К генеалогии морали // Собр. соч.: В 2 т. М.: Мысль, 1996. С. 455. 
яснению. Его представители считают историографию наукой и не склонны всерьез делать скидку на то, что эта наука конструирует свою действительность с помощью рассказа. Радикальный же историзм относится к историографии в первую очередь как к специфическому нарративу. Когда этот нарратив создается в критических целях, он, согласно Бевиру, может принимать форму генеалогии, если использовать это понятие в том значении, которое ему придавали Ницше и Фуко.

3. Взгляд на государство (view of the state). Поскольку девелопментальные истористы воспринимают государство как квазиорганическую сущность, они полагают естественными те социальные, культурные и нравственные связи, которые его образуют. Радикальные истористы, напротив, представляют государства как исторически случайные образования и подчеркивают их неустойчивый, дисперсный характер. В целом их подход Бевир считает децентрированным и безгосударственным.

Достоинство такой концепции радикального историзма состоит в том, что она поощряет конструктивистский подход к осмыслению прошлого и создает почву для номиналистической онтологии истории, максимально свободной как от догматических предпосылок, так и от авторитета «неоспоримых фактов». Контингентость исторических событий делается здесь непременным условием их познаваемости. При этом познаваемость отождествляется с их денатурализацией, достигаемой посредством критических высказываний, обнаруживающих их случайную природу. Однако Бевир оставил в стороне вопрос о том, на что нацелена историческая критика, осуществляемая в виде генеалогии. На мой взгляд, она нацелена в сторону настоящего, в котором живет историк. И в этом, по моему убеждению, следует видеть главное отличие радикального историзма от его девелопментального аналога. Последний стремится легитимировать настоящее, выставляя его в качестве закономерного (если не ключевого) этапа некоторого долговременного развития. В то время как генеалогическая критика, как писал Фуко,

... в контингентности, которая сделала нас теми, кто мы есть, выделит возможность больше не быть теми, кто мы есть, не делать то, что мы делаем, или не мыслить то, что мы мыслим ${ }^{34}$.

34. Foucault M. What Is Enlightenment? // The Foucault Reader/ P. Rabinow (ed.). N.Y.: Pantheon Books, 1984. P. 46. 
Иными словами, производимый этой критикой исторический демонтаж той реальности, которую мы вынужденно признаем в качестве нашего настоящего, должен открывать путь освобождения от нее. Генеалогическая критика - Фуко прямо это говорит, — «насколько это возможно, стремится придать новый импульс работе свободы $\rangle^{35}$.

Несмотря на недюжинную проницательность, Бевир, по-видимому, просто не пожелал ${ }^{36}$ прояснить ряд очень важных вопросов, которые оставляет его анализ радикального историзма. К примеру, правильно ли считать, что последний является «более зрелым» историзмом по сравнению с девелопментальным? Ход рассуждений Бевира подсказывает, что это предположение неверно, поскольку появление радикального историзма не отменяет возможности писать историю в девелопментальном ключе. Следовательно, оба историзма могут существовать одновременно. Тогда почему радикальный историзм, по его мнению, заявляет о себе только в конце XIX - начале XX века? Что мешало ему возникнуть раньше? Бевир не только не отвечает на этот вопрос, но даже им не задается. Равно как не берется объяснить, какой темпоральный режим представляет собой альтернативу линеарному времени девелопментального историзма. Говоря о радикальном историзме Фуко, он вполне справедливо замечает, что «его генеалогия вводит темпоральную сложность и контингентность» ${ }^{37}$, но в дальнейшем даже не пытается пояснить, что под этим следует понимать. Мне думается, что «постаналитический» подход Бевира заслуживает того же упрека, какой Бевир адресует археологическому методу, практикуемому Фуко до своего обращения к генеалогии: он «не в состоянии объяснить, как происходит переход от одной эпистемы к другой» ${ }^{38}$. Бевир совершенно не прописывает характер отношений, в которых находятся две основные разновидности историзма: какие ценности определяют предпочтение одного историзма другому, какие институциональные практики закрепляют это предпочтение. Тем не менее я на-

35. Ibidem. Курсив мой. - A. O.

36. По-видимому, это нежелание объясняется природой его так называемой постаналитической (post-analytic) философии истории, которая пренебрегает всякой исторической контекстуализацией и этим решительно отличается от континентального историзма в любых его версиях. См.: Bevir M. Post-Analytic Historicism // Journal of the History of Ideas. 2012. Vol. 73. № 4. P. $657-665$.

37. Idem. Historicism and Critique. P. 236.

38. Ibidem. 
хожу чрезвычайно плодотворной интуицию, легшую в основание концепции Бевира. Развивая ее, ниже я предлагаю собственное, несколько расширенное понимание радикального историзма с акцентом на его «темпоральной сложности».

Мне представляется справедливым признавать за радикальный историзм такой темпоральный режим, который порывает с идеей онтологической несовместимости прошлого и настоящего и позволяет говорить о соприсутствии множества разновременных явлений в составе одного социально-исторического опыта. Возможно, первая удачная концептуализация этого темпорального режима была произведена Эрнстом Блохом и схвачена им в понятии «современность несовременного» (Gleichzeitigkeit des Ungleichzeitigen) ${ }^{39}$. В книге «Наследие этого времени», вышедшей в 1935 году, Блох объясняет приход к власти нацистов тем, что основной классовый антагонизм между рабочими и капиталистами осложнялся вмешательством других социальных сил, которые не были ему «современны». Была городская молодежь, лишенная ясного представления о собственном будущем, было крестьянство, сохраняющее свой архаический уклад, была обедневшая мелкая буржуазия, ностальгирующая по довоенному порядку и стабильности. Вообще Германия, по словам Блоха, была

... классической страной несовременности, то есть непреодоленных пережитков прежнего экономического бытия и сознания ${ }^{40}$.

Нацисты добились успеха, потому что, в отличие от левых, лучше чувствовали настроения этих слоев и смогли воспользоваться в своих интересах их «энергией», не только реакционной, но одновременно и протореволюционной.

Версия «исторического материализма», предложенная Вальтером Беньямином в его знаменитых «Тезисах о понятии истории» (1940), на мой взгляд, является еще одной чрезвычайно важной концептуализацией радикального историзма avant le lettre ${ }^{41}$.

39. Впервые это термин был использован искусствоведом Вильгельмом Пиндером. См.: Schwartz. F. J. Ernst Bloch and Wilhelm Pinder: Out of Sync// Grey Room. 2001. № 3. P. 54-89.

40. Bloch M. Erbschaft dieser Zeit. Fr.a.M.: Suhrkamp, 1962. S. 113.

41. Беньямин В. О понятии истории // Он же. Учение о подобии. Медиаэстетические произведения. М.: РГГУ, 2012. С. 237-253; Benjamin W. Gesammelte Werke. Bd I/2. Fr.a.M.: Suhrkamp, 1991. S. 690-708. 
Поток линейного времени классического историзма и стоящей за ним идеологии прогресса взрывается здесь революционным «временем-сейчас», Jetztzeit, в котором нынешний угнетенный класс встречается со своим прошлым и искупает его. И хотя Беньямин нигде отчетливо не формулирует идею множественности исторических времен, трудно не заметить, что прошлое и настоящее мыслятся им как во многом автономные времена. Если их встреча, никак не предуготовленная предшествующим ходом классовой борьбы, победа в которой неизменно достается угнетателям, все-таки происходит, то случается она в некий исключительный момент, «момент опасности», вызывающий остановку «пустого и гомогенного» времени прогресса и превращающий настоящее в асинхронное «время-сейчас», насыщенное фрагментами мессианского времени.

Луи Альтюссер, разработавший самую изощренную в марксистской традиции теорию множественного исторического времени, намеренно избегал именовать ее «радикальным историзмом». В работе «Читать „Капитал“» (1965) он припас этот термин для обозначения леваческого заблуждения, которому, как он считал, был подвержен Антонио Грамши, не видевший разницы между наукой истории (историческим материализмом) и марксистской философией (диалектическим материализмом). Марксизм, по убеждению Альтюссера, будучи наукой, не сводим к какому бы то ни было историзму и даже противоположен ему ${ }^{42}$. Тем не менее радикальный историзм sine nomine является именно той темпоральной структурой, которую выстраивает Альтюссер в этой книге как альтернативу гегелевской концепции исторического времени. Последняя характеризуется двумя чертами: 1) гомогенной континуальностью и 2) таким пониманием исторического настоящего, которое позволяет говорить о его современности самому себе в силу "сущностного среза» (coupe d'essence), представляющего собой

... интеллектуальную операцию, создающую вертикальный срез в любой момент в историческом времени, такой срез в настоящем, что все элементы целого благодаря ему обнаруживают непосредственную связь друг с другом, ту связь, которая выражает их внутреннюю сущность ${ }^{43}$.

42. См. главу "Marxism is not a Historicism" в работе: Althusser L., Balibar E. Reading "Capital". L.: NLB, 1970.

43. Ibid. P. 94 . 
Альтюссер полагал, что такая модель континуального и гомогенного времени, позаимствованная из вульгарного эмпиризма, «больше не может считаться временем истории» ${ }^{4}$. Ей он противопоставлял обнаруженную им в работах Маркса многослойную темпоральность социальной формации, где каждому отдельному уровню - производительным силам, производственным отношениям, политике, философии, искусству и т. д. - соответствует свое время и свой собственный ритм. Сплетение этих времен образует историческую актуальность, которую Альтюссер называл конъюнктурой. Всякая подобная конъюнктура является историческим образованием sui generis. Оно не выводимо из предшествующих конъюнктур. Его радикальная контингентность сопротивляется анализу в категориях диахронии и синхронии, необходимости и случайности. Оно одновременно судьбоносно и поддается коррекции, сверх- и не-детерминировано. Но в любом случае оно критично для порядка, претендующего на легитимность в гомогенном настоящем. В работах, изданных посмертно и посвященных так называемому алеаторному материализму, Альтюссер проясняет парадоксальную темпоральную структуру этого образования, воспользовавшись идеей благоприятного момента (occasione) из «Государя» Макиавелли, которая фигурирует там в качестве предварительного условия для возникновения нового государства. Альтюссер трактует occasione как то, что обеспечивает счастливое взаимодействие фортуны и доблести государя, которое может продлиться сколь угодно долго, а может оказаться очень коротким ${ }^{45}$. Свершившийся факт такого взаимодействия отнюдь не гарантирует его последующую длительность, скорее, указывает на его неизбежную временность. История, по словам Альтюссера,

...есть не что иное, как постоянное упразднение свершившегося факта другим еще неустановленным фактом. [Он будет упразд-

44. Ibid. P. 99. Примечательно, что даже знаменитый английский историк Эдвард Томпсон, непримиримый оппонент Альтюссера, выражал согласие с этой частью его критики. «Есть только один аргумент, который я нашел хорошим. Это альтюссеровская критика методов синхронизации» (Thompson E. P. The Poverty of Theory, or An Orrery of Errors. L.: Merlin, 1995. P. 137).

45. См.: Althusser L. The Underground Current of the Materialism of the Encounter// Idem. Philosophy of the Encounter. Later Writings, 1978-1987. L.: Verso, 2006. P. 163-207. 
нен] без нашего предварительного знания о том, как и когда произойдет то событие, которое его отменит, и произойдет ли оно вообще . $^{46}$.

Однако преимущество occasione перед virtù государя, который сумеет им воспользоваться, от этого нисколько не пострадает. Смысл occasione, как мне представляется, аналогичен понятию учредительной власти внутри традиции политической философии, возводимой обычно к аббату Сийесу, хотя в последнее время ее основателем все чаще объявляют Макиавелли ${ }^{47}$. Учредительная власть, как мы помним, имеет экстраправовую природу. Ее действие не исчерпывается принятием конституции и созданием институтов легальной власти. Будучи политической по преимуществу, она гораздо нагляднее заявляет о себе в ситуации социальных конфликтов, ставящих под сомнение легитимность этих институтов. По словам Филиппо дель Луккезе,

...учредительная власть берет начало в дисгармонии, конфликте расходящихся интересов и борьбе за другой социальный, политический и исторический порядок, который требует также нового правового порядка. <...> Ее живительную силу можно поддерживать, только признавая за ней совершенно конфликтную основу, сохраняющуюся внутри правого и политического измерения, и отказываясь отделять ее происхождение от ее исторического развития ${ }^{48}$.

Таким образом, если мы будем придерживаться кризисного понятия учредительной власти ${ }^{49}$, как это принято в теориях радикальной демократии, то мы должны признавать ее несводимость к учрежденной власти, а также не смешивать ее с понятием суве-

46. Ibid. P. 174.

47. См.: Del Lucchese F. Machiavelli and Constituent Power: The Revolutionary Foundation of Modern Political Thought//European Journal of Political Theory. 2014. Vol. 16. № 1. P. 1-21.

48. Ibid. P. 10.

49. В том, что учредительная власть является «понятием кризиса» или указывает в качестве необходимого своего условия на некоторый непримиримый социальный конфликт, сходятся многие современные левые теоретики. См., напр.: Negri A. Insurgencies: Constituent Power and the Modern State. Minneapolis: University of Minnesota Press, 1999. P. 1-36; Abensour M. Democracy Against the State: Marx and the Machiavellian Movement. Cambridge: Polity Press, 2011; Del Lucchese F. Op. cit. 
ренитета ${ }^{50}$. Соответствующим образом должна отличаться также их темпоральная логика. Это отличие, на мой взгляд, было очень точно схвачено Антонио Негри:

В понятии учредительной власти заложена идея, что прошлое больше не объясняет настоящее, и только будущее сможет его объяснить ${ }^{51}$.

Важно понимать, что речь здесь не о том, что будущее побеждает прошлое в их споре за то, чем лучше объясняется настоящее. Скорее, будущее здесь одерживает верх над настоящим, которому прошлое до сих пор беспрекословно подчинялось, выступая инструментом (само)объяснения. Это подчинение уходит корнями в раннее Новое время - в ту эпоху, когда рождается концепция суверенной власти. Суверенная власть строится не только на примате территориальной целостности. Она заявляет о своей монополии на настоящее время, отличая его от прошедшего времени. Как показывает это в своих работах американский интеллектуальный историк Константин Фазолт, идея несовместимости порядков прошлого и настоящего не есть максима здравого смысла ${ }^{52}$. Она является политическим изобретением религиозных реформаторов и гуманистов, оспаривавших универсалистские притязания папства и Священной Римской империи и отказавших им в праве считаться современными институтами. И хотя прошлое тем самым выводилось из состава современности и деактуализировалось, оно одновременно становилось важнейшим инструментом легитимации той власти, которая господствует в настоящем и стремится совпасть с ним. Объясняя настоящее, демонстрируя его закономерность и необратимость, прошлое, по сути, обездвиживает его, лишает его качества времени.

50. На этом особенно настаивает Негри: «Понятия суверенитета и учредительной власти абсолютно противоположны друг другу. Мы можем поэтому заключить, что если существует независимый способ разворачивания понятия учредительной власти, то он исключает какие бы то ни было отсылки к понятию суверенитета» (Negri A. Op. cit. P. 21).

51. Ibid. P. 10.

52. См.: Fasolt C. The Limits of History. Chicago: University of Chicago Press, 2004. Рекомендую также мою рецензию на последнюю книгу этого чрезвычайно оригинального американского теоретика истории: Олейников А. Историк против историзма: случай Константина Фазолта // Новое литературное обозрение. 2018. № 2. С. 312-319. 
Будущее объясняет настоящее совсем по-другому. Оно позволяет увидеть в нем стечение разнородных обстоятельств, счастливый союз которых не может длиться вечно. Будущее отказывает настоящему в легитимности, но зато утверждает его радикальную новизну и исключительность. Такой взгляд на настоящее позволяет современной теории истории совершить макиавеллиевское «возвращение к началам» (ridurre ai principii) и заново осознать свои милленаристские истоки. Ведь, как замечает Джон Покок, именно благодаря раннехристианским нонконформистам, выступавшим против союза церкви и светской власти, появляются первые представления об альтернативной истории, события которой ожидались в самом ближайшем будущем:

Апокалиптическая история изображала время как ряд наделенных уникальной значимостью моментов, в которых любому коллективу людей может выпасть важнейшая роль, подобная той, что выпала Израилю или Риму ${ }^{53}$.

По мнению американского социолога Джона Холла, апокалиптический дискурс и соответствующая ему темпоральность остаются весьма востребованными на всем протяжении модерна ${ }^{54}$, особенно тогда, когда масштабные социальные потрясения побуждают людей действовать беспрецедентным образом, выходя за границы повседневной рутины:

Не будучи действительным концом мира, апокалипсис обычно является «концом мира, каким мы его знаем», чрезвычайным социальным и культурным разладом, драматические события которого немедленно меняют отношение множества людей к истории ${ }^{55}$.

Из этой цитаты могло бы показаться, что апокалиптический дискурс представляет собой один из модерных способов переживания социальной травмы или еще одну версию эстети-

53. Покок Дж. Момент Макиавелли. М.: НЛО, 2020. С. 162.

54. Покок также отмечает, что «апокалиптика служила мощным инструментом секуляризации, средством вернуть процесс искупления в измерение социального времени, от которого Августин попытался его отделить, и изобразить его как продолжение или преобразование существующих земных процессов» (Там же. С. 89).

55. Hall J. R. Apocalypse in the Long Run: Reflections on Huge Comparisons in the Study of Modernity// Sociological Research Online. 2010. Vol. 14. № 5. URL: https://www.socresonline.org.uk/14/5/10.html. 
ки возвышенного ${ }^{56}$. Однако Холла интересует совсем другое. Он полагает, что изучение апокалиптического дискурса может способствовать преодолению парадигмы всеобего объективного времени истории, структурированного посредством хронологии, и замене ее «социальной феноменологией», способной объяснять связь отдельных исторических темпоральностей между собой ${ }^{57}$.

В заключение еще раз напомню мой основной тезис. Возвращение интереса к темпоральной структуре исторического знания открывает перспективу его «реполитизации». Выше я постарался показать, каковы два ее важнейших модуса: а) критика «естественной» несовместимости прошлого и настоящего; б) радикальный историзм. Последний, отвечая на вызов презентизма, строится на предпосылке существования множественного исторического времени, а вводимая им событийность имеет ретроактивный характер, то есть определяется через примат будущего над настоящим.

\section{Библиография}

Анкерсмит Ф. Возвышенный исторический опыт. М.: Европа, 2007.

Бевернаж Б. Аллохронизм, равенство во времени и современность. Критика проекта радикальной современности Йоханнеса Фабиана и доводы в пользу новой политики времени // Социология власти. 2016. № 2. C. 174-202.

Беньямин В. О понятии истории // Он же. Учение о подобии. Медиаэстетические произведения. М.: РГГУ, 2012. С. 237-253.

Ницше Ф. К генеалогии морали // Собр. соч.: В 2 т. М.: Мысль, 1996.

Олейников А. Историк против историзма: случай Константина Фазолта // Новое литературное обозрение. 2018. № 2. С. 312-319.

Олейников А. Откуда берется прошлое? (Апология анахронизма)//Новое литературное обозрение. 2014. № 2. С. 337-344.

Покок Дж. Момент Макиавелли. М.: НЛО, 2020.

Abensour M. Democracy Against the State: Marx and the Machiavellian Movement. Cambridge: Polity Press, 2011.

Althusser L. The Underground Current of the Materialism of the Encounter// Idem. Philosophy of the Encounter. Later Writings, 1978-1987. L.: Verso, 2006. P. 163-207.

Althusser L., Balibar É. Reading “Capital”. L.: NLB, 1970.

Benjamin W. Gesammelte Werke. Fr.a.M.: Suhrkamp, 1991. Bd I/2. S. 690-708.

Bevernage B. History, Memory, and State-Sponsored Violence: Time and Justice. L.; N.Y.: Routledge, 2012.

56. Как в известной работе Франка Анкерсмита. См.: Анкерсмит Ф. Возвышенный исторический опыт. М.: Европа, 2007.

57. Hall J.R. Op. cit. 
Bevir M. Historicism and Critique// Philosophy of the Social Sciences. 2015. Vol. 45. № 2. P. 227-245.

Bevir M. Post-Analytic Historicism// Journal of the History of Ideas. 2012. Vol. 73. № 4. P. 657-665.

Bevir M., Rhodes R. A. W. Three Visions of Context and History// Contest in Public History and Management: The Missing Link? / C. Pollit (ed.). Aldershot: Edward Elgar, 2013. P. 55-73.

Bloch M. Erbschaft dieser Zeit. Fr.a.M.: Suhrkamp, 1962.

Breaking Up Time: Negotiating the Borders Between Present, Past and Future / C. Lorenz, B. Bevernage (eds). Göttingen: Vandenhoeck \& Ruprecht, 2013.

De Certeau M. Heterologies: Discourse on the Other. Minneapolis: University of Minnesota Press, 1986.

De Certeau M. The Writing of History. N.Y.: Columbia University Press, 1988.

Del Lucchese F. Machiavelli and Constituent Power: The Revolutionary Foundation of Modern Political Thought// European Journal of Political Theory. 2014. Vol. 16. № 1. P. 1-21.

Fasolt C. The Limits of History. Chicago: University of Chicago Press, 2004.

Foucault M. What Is Enlightenment? // The Foucault Reader/ P. Rabinow (ed.). N.Y.: Pantheon Books, 1984.

Gumbrecht H. U. Our Broad Present: Time and Contemporary Culture. N.Y.: Columbia University Press, 2014.

Habermas J. Concerning the Public Use of History// New German Critique. 1988. № 44 (Special Issue on the Historikerstreit). P. 40-50.

Habermas J. Eine Art Schadensabwicklung. Die apologetischen Tendenzen in der deutschen Zeitgeschichtsschreibung // Historikerstreit. Die Dokumentation der Kontroverse um die Einzigartigkeit der nationalsozialistischen Judenvernichtung. München; Zürich: Piper, 1987. S. 62-76.

Hall J. R. Apocalypse in the Long Run: Reflections on Huge Comparisons in the Study of Modernity // Sociological Research Online. 2010. Vol. 14. № 5. URL: http://socresonline.org.uk/14/5/10.html.

Hartog F. Regimes of Historicity. Presentism and the Experiences of Time. N.Y.: Columbia University Press, 2015.

Kleinberg E., Scott J. W., Wilder G. Theses on Theory and History. URL: http:// theoryrevolt.com.

Koposov N. Memory Laws, Memory Wars: The Politics of the Past in Europe and Russia. Cambridge: Cambridge University Press, 2018.

Landwehr A. Geburt der Gegenwart. Eine Geschichte der Zeit im 17. Jahrhundert. Fr.a.M.: Fischer, 2014.

Landwehr A. Nostalgia and the Turbulence of Times// History and Theory. 2018. Vol. 57. № 2. P. 251-268.

Lorenz C. 'The Times They Are a-Changin'. On Time, Space and Periodization in History// Palgrave Handbook of Research in Historical Culture and Education / M. Carretero, S. Berger, M. Grever (eds). L.: Palgrave Macmillan, 2017. P. 109-131.

Negri A. Insurgencies: Constituent Power and the Modern State. Minneapolis: University of Minnesota Press, 1999.

Nolte E. Vergangenheit, die nicht vergehen will// Historikerstreit. Die Dokumentation der Kontroverse um die Einzigartigkeit der nationalsozialistischen Judenvernichtung. München; Zürich: Piper, 1987. S. $39-46$. 
Norton C., Donnelly M. Liberating Histories. L.: Routhledge, 2018.

Schiffman Z.S. The Birth Of The Past. Baltimore: Johns Hopkins University Press, 2011.

Schwartz. F. J. Ernst Bloch and Wilhelm Pinder: Out of Sync// Grey Room. 2001. № 3. P. 54-89.

Tamm M., Olivier L. Introduction. Rethinking Historical Time// Rethinking Historical Time. New Approaches to Presentism/M. Tamm, L. Olivier (eds). L.: Bloomsbury Academic, 2019. P. 1-20.

Tanaka S. History Without Chronology. Amherst, MA: Lever Press, 2019.

Thompson E. P. The Poverty of Theory, or An Orrery of Errors. L.: Merlin, 1995. West-Pavlov R. Temporalities. L.; N.Y.: Routledge, 2013.

White H. The Modernist Event// Idem. Figural Realism. Studies in the Mimesis Effect. Baltimore: Johns Hopkins University Press, 1999. P. 66-86.

White $\mathrm{H}$. The Politics of Historical Interpretation: Discipline and De-Sublimation // Critical Inquiry. 1982. Vol. 9. № 1. P. 113-137.

White H. The Practical Past. Evanston, IL: Northwestern University Press, 2014. 


\section{HISTORY'S TIME}

Andrey Oleynikov. Head, Department of Political and Legal Studies, Faculty of Political Sciences; Senior Researcher, SHAGI Center for Studies in History and Culture, School for Advanced Studies in the Humanities (SASH), Institute for Social Sciences (ISS), andrey.oleynikov@gmail.com.

Moscow School of Social and Economic Sciences (MSSES), 3-5 Gazetny Lane, 125009 Moscow, Russia.

Russian Presidential Academy of National Economy and Public Administration (RANEPA), 82 Vernadskogo Ave., 119571 Moscow, Russia.

Keywords: temporal turn; multiple temporality; practical past; radical historicism; constituent power; retroactivity; contingency.

The article maintains that the so-called temporal turn that has recently taken hold in the theory of history expands the subject matter of academic historiography (allowing it to include the previously little-studied ways of experiencing and ordering time during the eras that preceded the institutionalization of historical knowledge and the formation of classical historicism's linear temporality), while also eliciting questions about its practical purpose and "the use and abuse of history in life." The author suggests using Michel de Certeau's idea from the 1980s of repoliticizing historiography as a way to gain insight into this topic.

The author finds that repoliticization adopted as a research strategy can be deployed in two modes: a) as a critique of professional historiography's ambition to obtain maximally objective knowledge about a past which is considered fundamentally different from the present and incompatible with it; and b) as a special practiceoriented philosophy of history, which is to be called "radical historicism." In the first use of repoliticization, the criticism is along the lines of studying the "practical past" as Hayden White advocated in his book of that title, the last one to be published before his death. In it he exposed the antagonism between the historical past that is created by professional historians and the practical past that is available to anyone without exception. The author proposes his own approach to the concept of radical historicism, inspired by Mark Bevir's writings as well as by the ideas of a number of famous Marxist thinkers and theorists of radical democracy. Generally speaking, radical historicism holds to a contingent ontology of the historical event (its radical novelty) and a rejection of the present state of affairs (in which the historian lives) as a "natural" or "legitimate" configuration of historical forces and processes.

DOI: $10.22394 / 0869-5377-2021-4-5-27$

\section{References}

Abensour M. Democracy Against the State: Marx and the Machiavellian Movement, Cambridge, Polity Press, 2011.

Althusser L. The Underground Current of the Materialism of the Encounter. Philosophy of the Encounter. Later Writings, 1978-1987, London, Verso, 2006, pp. 163-207.

Althusser L., Balibar É. Reading “Capital”, London, NLB, 1970.

Ankersmit F. Vozvyshennyi istoricheskii opyt [Sublime Historical Experience], Moscow, Europe, 2007.

Benjamin W. Gesammelte Werke, Frankfurt am Main, Suhrkamp, 1991, Bd. I/2, S. $690-708$. 
Benjamin W. O poniatii istorii [Über den Begriff der Geschichte]. Uchenie o podobii. Mediaesteticheskie proizvedeniia [Doctrine of the Similar. Mediaesthetic Works], Moscow, RSUH, 2012, pp. 237-253.

Bevernage B. Allokhronizm, ravenstvo vo vremeni i sovremennost'. Kritika proekta radikal'noi sovremennosti Iokhannesa Fabiana i dovody v pol'zu novoi politiki vremeni [Allochronism, Coevalness and the Contemporary. A Critique of Johannes Fabian's Project of Radical Contemporaneity and a Plea for a New Politics of Time]. Sotsiologiia vlasti [Sociology of Power], 2016, no. 2, pp. 174-202.

Bevernage B. History, Memory, and State-Sponsored Violence: Time and Justice, London, New York, Routledge, 2012.

Bevir M. Historicism and Critique. Philosophy of the Social Sciences, 2015, vol. 45, no. 2, pp. 227-245.

Bevir M. Post-Analytic Historicism. Journal of the History of Ideas, 2012, vol. 73, no. 4 , pp. $657-665$.

Bevir M., Rhodes R. A. W. Three Visions of Context and History. Contest in Public History and Management: The Missing Link? (ed. C. Pollit), Aldershot, Edward Elgar, 2013, pp. 55-73.

Bloch M. Erbschaft dieser Zeit, Frankfurt am Main, Suhrkamp, 1962.

Breaking Up Time: Negotiating the Borders Between Present, Past and Future (eds C. Lorenz, B. Bevernage), Göttingen, Vandenhoeck \& Ruprecht, 2013.

De Certeau M. Heterologies: Discourse on the Other, Minneapolis, University of Minnesota Press, 1986.

De Certeau M. The Writing of History, New York, Columbia University Press, 1988.

Del Lucchese F. Machiavelli and Constituent Power: The Revolutionary Foundation of Modern Political Thought. European Journal of Political Theory, 2014, vol. 16 , no. 1 , pp. 1-21.

Fasolt C. The Limits of History. Chicago: University of Chicago Press, 2004.

Foucault M. What Is Enlightenment?. The Foucault Reader (ed. P. Rabinow), New York, Pantheon Books, 1984.

Gumbrecht H. U. Our Broad Present: Time and Contemporary Culture, New York, Columbia University Press, 2014.

Habermas J. Concerning the Public Use of History. New German Critique, 1988, no. 44 (Special Issue on the Historikerstreit), pp. 40-50.

Habermas J. Eine Art Schadensabwicklung. Die apologetischen Tendenzen in der deutschen Zeitgeschichtsschreibung. Historikerstreit. Die Dokumentation der Kontroverse um die Einzigartigkeit der nationalsozialistischen Judenvernichtung, München, Zürich, Piper, 1987, S. 62-76.

Hall J. R. Apocalypse in the Long Run: Reflections on Huge Comparisons in the Study of Modernity. Sociological Research Online, 2010, vol. 14, no. 5. Available at: http://socresonline.org.uk/14/5/10.html.

Hartog F. Regimes of Historicity. Presentism and the Experiences of Time, New York, Columbia University Press, 2015.

Kleinberg E., Scott J. W., Wilder G. Theses on Theory and History. Available at: http://theoryrevolt.com.

Koposov N. Memory Laws, Memory Wars: The Politics of the Past in Europe and Russia, Cambridge, Cambridge University Press, 2018.

Landwehr A. Geburt der Gegenwart. Eine Geschichte der Zeit im 17. Jahrhundert, Frankfurt am Main, Fischer, 2014. 
Landwehr A. Nostalgia and the Turbulence of Times. History and Theory, 2018, vol. 57, no. 2, pp. 251-268.

Lorenz C. 'The Times They Are a-Changin'. On Time, Space and Periodization in History. Palgrave Handbook of Research in Historical Culture and Education (eds M. Carretero, S. Berger, M. Grever), London, Palgrave Macmillan, 2017, pp. 109-131.

Negri A. Insurgencies: Constituent Power and the Modern State, Minneapolis, University of Minnesota Press, 1999.

Nietzsche F. K genealogii morali [Zur Genealogie der Moral]. Sobr. soch.: V 2 t. [Collected Works: In 2 vols], Moscow, Mysl', 1996.

Nolte E. Vergangenheit, die nicht vergehen will. Historikerstreit. Die Dokumentation der Kontroverse um die Einzigartigkeit der nationalsozialistischen Judenvernichtung, München, Zürich, Piper, 1987, S. 39-46.

Norton C., Donnelly M. Liberating Histories, London, Routhledge, 2018.

Oleynikov A. Istorik protiv istorizma: sluchai Konstantina Fazolta [A Historian Against Historicism: Constantin Fasolt's Case]. Novoe literaturnoe obozrenie [New Literary Observer], 2018, no. 2, pp. 312-319.

Oleynikov A. Otkuda beretsia proshloe? (apologiia anakhronizma) [Where Does the Past Come From? (Apology of Anachronism)]. Novoe literaturnoe obozrenie [New Literary Observer], 2014, no. 2, pp. 337-344.

Pocock J. Moment Makiavelli [The Machiavellian Moment], Moscow, New Literary Observer, 2020.

Schiffman Z.S. The Birth Of The Past, Baltimore, Johns Hopkins University Press, 2011.

Schwartz. F. J. Ernst Bloch and Wilhelm Pinder: Out of Sync. Grey Room, 2001, no. 3, pp. 54-89.

Tamm M., Olivier L. Introduction. Rethinking Historical Time. Rethinking Historical Time. New Approaches to Presentism (eds M. Tamm, L. Olivier), London, Bloomsbury Academic, 2019, pp. 1-20.

Tanaka S. History Without Chronology, Amherst, MA, Lever Press, 2019.

Thompson E. P. The Poverty of Theory, or An Orrery of Errors, London, Merlin, 1995.

West-Pavlov R. Temporalities, London, New York, Routledge, 2013.

White H. The Modernist Event. Figural Realism. Studies in the Mimesis Effect, Baltimore, Johns Hopkins University Press, 1999, pp. 66-86.

White $\mathrm{H}$. The Politics of Historical Interpretation: Discipline and De-Sublimation. Critical Inquiry, 1982, vol. 9, no. 1, pp. 113-137.

White H. The Practical Past, Evanston, IL, Northwestern University Press, 2014. 